\title{
Mössbauer spectroscopy and X-ray diffraction studies of ball-milling-induced transformations of a near-equiatomic FeV sigma phase: Influence of oxygen
}

\author{
B.F.O. Costa ${ }^{\mathrm{a}, *}$, G. Le Caër ${ }^{\mathrm{b}}$, B. Malaman ${ }^{\mathrm{c}}$, A.C. Batista ${ }^{\mathrm{a}}$ \\ ${ }^{a}$ Department of Physics, University of Coimbra, P-3004-516 Coimbra, Portugal \\ ${ }^{\mathrm{b}}$ GMCM UMR CNRS 6626, Université de Rennes I, Campus de Beaulieu, Bat 11A, F-35042 Rennes Cedex, France \\ ${ }^{\mathrm{c}}$ LCSM UMR CNRS 7555, Université Henri Poincaré-Nancy I, BP239, F-54506 Vandoeuvre-les-Nancy Cedex, France
}

Available online 16 May 2007

\begin{abstract}
${ }^{57} \mathrm{Fe}$ Mössbauer spectroscopy and X-ray diffraction were used to study the structural changes induced by ball milling a coarse-grained $\mathrm{Fe}_{48.1} \mathrm{~V}_{51.9}$ at \% sigma phase in a vibratory mill in argon with a frequent gas renewal. The sigma phase transforms into a bcc alpha phase till $140 \mathrm{~h}$ of milling. Mössbauer spectroscopy also shows the presence of an amorphous phase. Further, X-ray diffraction and Mössbauer spectroscopy reveals the presence of a corundum type oxide $\left(\mathrm{V}_{1-x} \mathrm{Fe}_{x}\right)_{2} \mathrm{O}_{3}$ and of a spinel $\mathrm{FeV}_{2} \mathrm{O}_{4}$ in samples milled for $140 \mathrm{~h}$ and longer. Mössbauer spectroscopy clearly shows that the spinel phase starts to form after $140 \mathrm{~h}$ of milling. Oxidation is progressive and occurs first via an unmixing process which deprives the $\mathrm{Fe}-\mathrm{V}$ bcc matrix of vanadium atoms.
\end{abstract}

(C) 2007 Elsevier B.V. All rights reserved.

PACS: 76.80. + y; 61.10.-I; 61.82.Bg; 61.82.Rx

Keywords: Mössbauer spectroscopy; X-ray diffraction; Fe-V alloys; Ball milling; Spinel structure

\section{Introduction}

According to the Fe-V phase diagram, a disordered bcc solid solution (alpha phase) is formed over a broad concentration range at high temperature but is interrupted at temperatures below $1525 \mathrm{~K}$ by the presence of the sigma phase which is tetragonal, for near equiatomic compositions [1]. A similar brittle phase, also formed in $\mathrm{Fe}-\mathrm{Cr}$ alloys, is for instance detrimental to their mechanical behavior. A metastable ordered compound $\mathrm{FeV}$ with a structure of the $\mathrm{B} 2$ type $(\mathrm{CsCl})$ is rather easily formed [1-3].

In nanocrystalline materials, phase transformations may differ from those of classical materials (transformation kinetics, metastable phases, etc.). Differences were reported, for instance, for $\mathrm{Fe}-\mathrm{Cr}$ and $\mathrm{Fe}-\mathrm{Cr}-\mathrm{Sn}$ alloys $[4,5]$ and for nearly equiatomic $\mathrm{Fe}-\mathrm{V}$ alloys for which the formation of a metastable B2 alloy competes with that of a sigma phase [2].

\footnotetext{
*Corresponding author. Tel.: + 351 239410630; fax: + 351239829158

E-mail address: Benilde@ci.uc.pt (B.F.O. Costa).
}

Phase transformations driven by plastic deformation (ball milling, severe plastic deformation, cold rolling, etc.) are both of fundamental and applied interest [6-13].

Mechanical alloying of concentrated blends of $\mathrm{Fe}$ and $\mathrm{V}$ powders in a conventional ball mill, in argon atmosphere, yields a bcc alpha phase instead of sigma although it is stable at $300 \mathrm{~K}[14,15]$. Further, an amorphous $\mathrm{Fe}-\mathrm{V}$ alloy [16] or a mixture of an alpha phase and of an amorphous phase [17] were also reported to form by mechanically alloying. Ball milling of the alpha FeV phase transforms it into an alpha phase, in argon $[13,14]$ or in vacuum $[7,8]$.

However, a contamination of the ground powders by residual gases or by the materials constituting the milling tools, may drive the transformation to a final state which differs from the one that would be reached by the sole action of shearing.

In the present paper, we describe the influence of oxygen on the evolution of a nearly equiatomic $\mathrm{Fe}-\mathrm{V}$ alpha phase when it is ground in a vibratory mill in argon with a frequent gas replacement. 


\section{Experimental}

A sigma phase $\mathrm{Fe}_{48.1} \mathrm{~V}_{51.9}$ at\% alloy was ball milled in a Fritsch P0 vibratory mill. The starting alloy was prepared by melting together, in argon, appropriate amounts of $\mathrm{Fe}$ and $\mathrm{V}$ in an induction furnace. The composition is close to that studied by Bakker et al. [7,8]. The as-cast alloy consists of a bcc phase. The sigma phase was then formed by annealing the as-cast alloy in vacuum at $1000^{\circ} \mathrm{C}$ for $100 \mathrm{~h}$. The brittle sigma phase was finally powdered with a pestle in an agate mortar. A mass of about $5 \mathrm{~g}$ of alpha-FeV was ball milled in accumulated milling times under argon atmosphere in a Fritsch P0 mill working at its maximum amplitude of vibration ( 3 in. scale).

$\mathrm{X}$-ray diffraction $(\mathrm{XRD})$ was performed at room temperature (RT) using $\mathrm{CuK} \alpha$ radiation $(\lambda=0.15406 \mathrm{~nm})$ to characterize the microstructural changes induced by ball milling.

Mössbauer spectroscopy was also used to follow the phase evolution. ${ }^{57} \mathrm{Fe}$ spectra were recorded at RT in a transmission geometry using a standard constant acceleration spectrometer. A ${ }^{57} \mathrm{Co}$ source in $\mathrm{Rh}$ matrix with a strength of $\approx 25 \mathrm{mCi}$ was used. The spectra were analyzed by a constrained Hesse-Rübartsch method [18], which yields a hyperfine magnetic field distribution. Lorentzian line-shapes were employed in this procedure. The ${ }^{57} \mathrm{Fe}$ isomer shifts are given with respect to $\alpha-\mathrm{Fe}$ at RT.

Differential scanning calorimetry was used to study the transformations of the samples milled for 140 and $200 \mathrm{~h}$ which occur during heating in an argon flow from RT to $900{ }^{\circ} \mathrm{C}$ with a heating rate of $40^{\circ} \mathrm{C} / \mathrm{min}$.

\section{Results and discussion}

Chemical compositions were determined by microprobe analysis. They are $\mathrm{Fe}_{48.1} \mathrm{~V}_{51.9}$ at $\%$ and $\mathrm{Fe}_{52.3} \mathrm{~V}_{47.7}$ at $\%$ for the starting sigma phase and for the final sample milled for $200 \mathrm{~h}$, respectively. The oxygen content of the latter sample is at least $6 \mathrm{wt} \%$. Contamination by steel and by oxygen is thus evidenced.

Fig. 1 shows the XRD patterns of FeV after different milling periods. After $5 \mathrm{~h}$ of milling, the main effect is the broadening of the XRD peaks of the starting sigma phase which reveals a refinement of the mean crystallite size. After $30 \mathrm{~h}$, a pattern of the bcc phase is already observed. Ground samples remain bcc for longer milling times but the peaks are broadened due to a reduction of crystallite size and to the effect of strain. The formation of the bcc phase by milling a near-equiatomic sigma $\mathrm{FeV}$ phase was already reported by Bakker et al. [7,8]. For prolonged milling, from 160 to $200 \mathrm{~h}$, we observe that a corundumtype oxide $\left(\mathrm{V}_{1-x} \mathrm{Fe}_{x}\right)_{2} \mathrm{O}_{3}$ and a spinel $\mathrm{FeV}_{2} \mathrm{O}_{4}$ form.

Fig. 2 shows RT ${ }^{57} \mathrm{Fe}$ Mössbauer spectra for samples milled for the indicated periods. The starting sigma phase is paramagnetic at RT with a mean isomer shift $\langle$ IS\& $\rangle=$ $-0.20 \mathrm{~mm} / \mathrm{s}$. With increasing milling time, a magnetic component appears. It represents $72 \%$ of the spectral area at $140 \mathrm{~h}$ of milling. Its mean hyperfine field, $\langle B\rangle$, first a

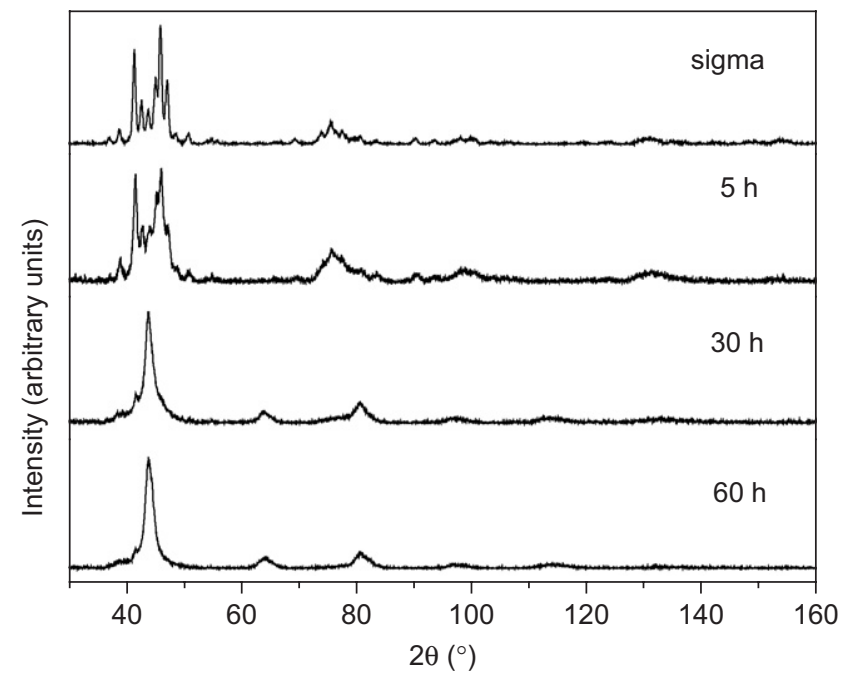

b

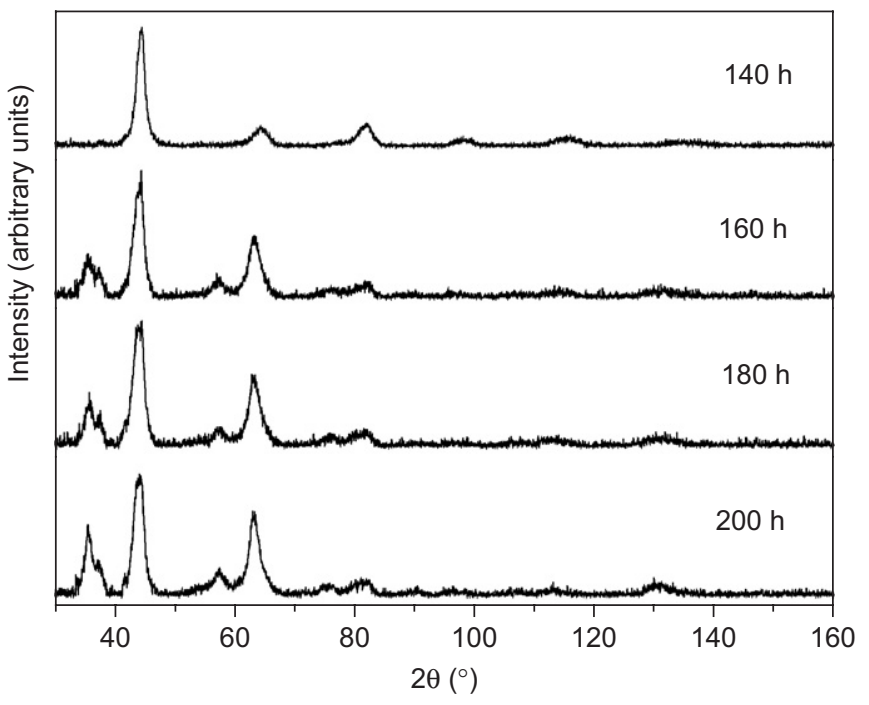

Fig. 1. X-ray diffraction patterns of an FeV sample milled for the indicated periods. The top pattern is that of the starting tetragonal sigma phase.

increases, up to $26.8 \mathrm{~T}$ for $180 \mathrm{~h}$ of milling. Then, it decreases to $18.7 \mathrm{~T}$ in a sample milled for $200 \mathrm{~h}$. Between $\sim 30$ and $120 \mathrm{~h}$ of milling, the hyperfine magnetic field distribution (HFMD) of that component shows a narrow peak at a field which is identical with or close to the field of alpha-Fe at RT and a broad and almost featureless band from $\sim 10$ to $\sim 30 \mathrm{~T}$ (Fig. 2) as seen also for HMFDs of binary mixtures of elemental powders of $\mathrm{Fe}$ and of various $\mathrm{T}$ elements during the early steps of the mechanically alloying process $[19,20]$. The fact that HMFDs with such features are observed here is somewhat surprising as $\mathrm{Fe}$ and $\mathrm{V}$ atoms are already chemically combined at the atomic scale in the starting sigma phase while they are unmixed in the starting elemental powder blends of the aforementioned $\mathrm{Fe}_{1-x} \mathrm{~T}_{x}$ systems $[19,20]$. The latter results were consistent with nanometer sized $\mathrm{Fe}$-rich regions separated from either T-rich zones or other phases already 


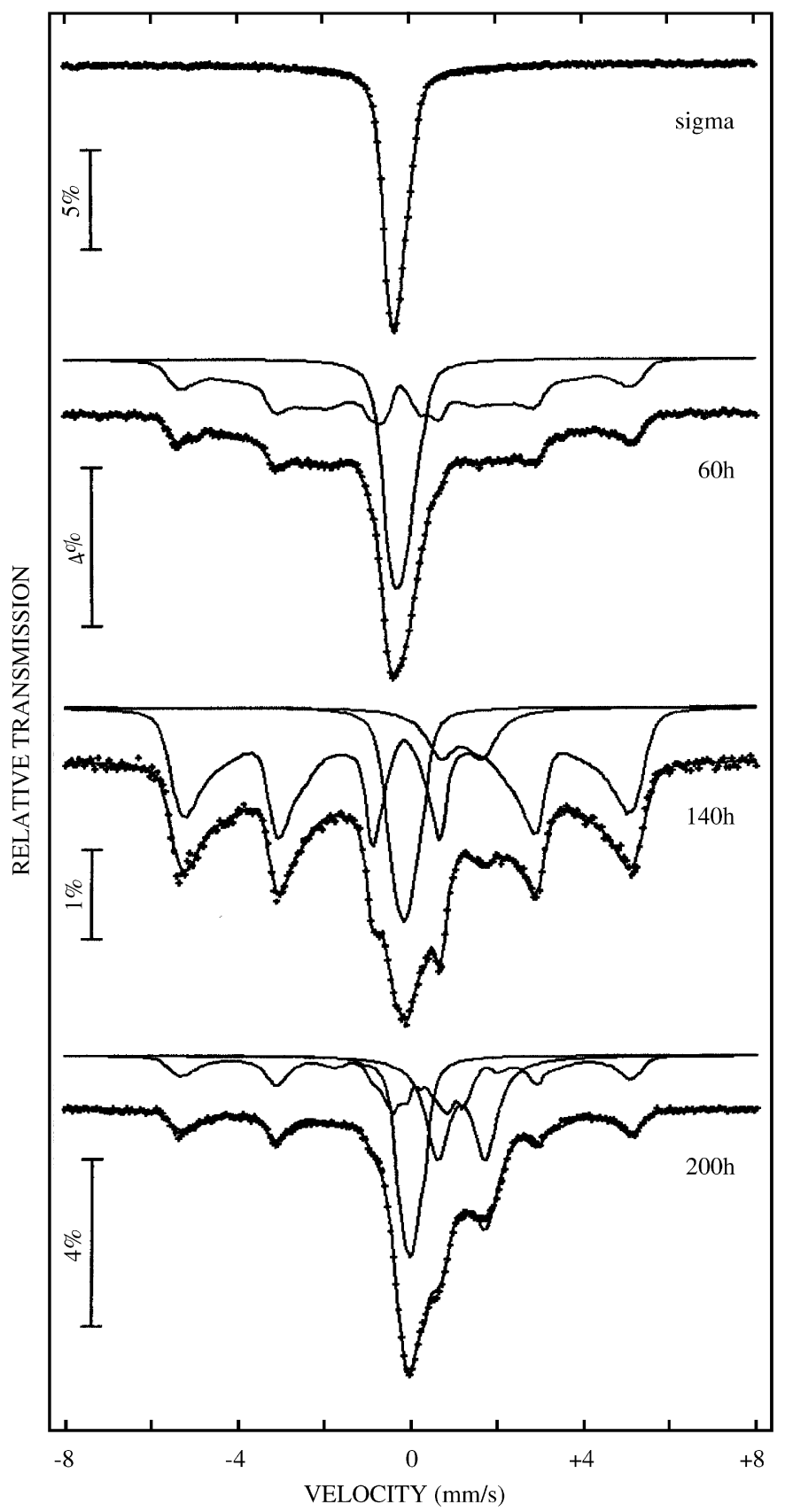

Fig. 2. ${ }^{57} \mathrm{Fe}$ Mössbauer spectra of the FeV sigma phase milled for the indicated periods.

formed by very rough interfaces, characterized at the atomic scale by distributions of lengths of flat regions and of step heights $[19,20]$. In any case, the transformation by milling of the FeV sigma phase into a bcc phase in the present conditions is not polymorphic. In the case of a transformation without composition change, we would expect to observe a spectrum similar to the one shown by Fig. 6 of [21] for an as-milled bcc $\mathrm{Fe}_{53} \mathrm{~V}_{47}$ alloy for which the mean field of the sole magnetic part is $14.3 \mathrm{~T}$ at RT [21]. Its HMFD consists essentially of a narrow peak at $\sim 1 \mathrm{~T}$, which accounts actually for the intense central peak of the spectrum, and of a broad Gaussian-like peak centered on a field of $14.3 \mathrm{~T}$. The bcc phase which forms here is clearly heterogeneous. The large value of the magnetic fraction ( $72 \%$ of the total area for $140 \mathrm{~h}$ of milling) rules out the hypothesis that a significant role might be played by iron contamination in the observed evolution.

The relative area of the paramagnetic component decreases with milling time and its mean isomer shift $\langle$ IS $\rangle$ changes, being already $-0.039 \mathrm{~mm} / \mathrm{s}$ for $140 \mathrm{~h}$ of milling ( $18 \%$ of the spectrum), suggesting that it is no longer related to the sole sigma phase but also to an additional amorphous phase [17]. The spectrum of the sample milled for $140 \mathrm{~h}$ was fitted with a supplementary doublet with a quadrupole splitting QS $=0.96 \mathrm{~mm} / \mathrm{s}$ and an isomer shift IS $=1.3 \mathrm{~mm} / \mathrm{s}$. This doublet represents $10 \%$ of the spectral area and is attributed to the presence of a ternary oxide. For longer milling times, the relative area of the paramagnetic subspectrum and the mean $\langle$ IS $\rangle$ increase, being $29 \%$ and $0.10 \mathrm{~mm} / \mathrm{s}$, respectively, for $200 \mathrm{~h}$ of milling. For this sample the doublet represents $33 \%$ of the area and has QS = $1.11 \mathrm{~mm} / \mathrm{s}$ and $\mathrm{IS}=1.29 \mathrm{~mm} / \mathrm{s}$. These values are consistent with the presence of a spinel $\mathrm{FeV}_{2} \mathrm{O}_{4}$ as deduced from the XRD pattern. The formation of such an oxide is consistent with the large amount of oxygen present in the sample. The progressive increase of the isomer shift of the paramagnetic component may be attributed to the formation of a corundum-type oxide, as deduced from XRD, $\left(\mathrm{V}_{1-x} \mathrm{Fe}_{x}\right)_{2} \mathrm{O}_{3}$ whose IS at RT are 0.38 and $0.51 \mathrm{~mm} / \mathrm{s}$ for $x=1$ and for $x=0.3$, respectively [22]. Differential scanning c alorimetry traces obtained for the samples milled for 140 and $200 \mathrm{~h}$ show a peak at around $600^{\circ} \mathrm{C}$. We have annealed the samples milled for 140 and $200 \mathrm{~h}$ isothermally at $600^{\circ} \mathrm{C}$. After $6 \mathrm{~min}$ of annealing, Mössbauer results show that the amorphous phase in the sample milled for $140 \mathrm{~h}$ crystallizes as the area of the central single line is drastically reduced.

From XRD patterns and RT Mössbauer spectra, we conclude that the sample milled for $200 \mathrm{~h}$ and annealed at $600{ }^{\circ} \mathrm{C}$ is composed of four phases, namely bcc-Fe, fcc-Fe, a corundum type oxide, $\left(\mathrm{V}_{1-x} \mathrm{Fe}_{x}\right)_{2} \mathrm{O}_{3}$ with $x$ of the order of 0.3 , and a spinel $\mathrm{FeV}_{2} \mathrm{O}_{4}$. These results will be described in more detail in a forthcoming paper.

\section{Conclusions}

A near-equiatomic $\mathrm{FeV}$ sigma phase transforms by milling in our conditions first into a bcc alpha phase, which is magnetic at RT. RT Mössbauer spectra show not only the appearance of a magnetic heterogeneous bcc phase but also reveal the presence of a single line due to a nonmagnetic phase which differs from the sigma phase. The latter component is due to an amorphous phase until $140 \mathrm{~h}$ of milling, but beyond, it can no longer be attributed solely to an amorphous phase as it does not disappear at the crystallization temperature revealed by calorimetry. Ternary oxides with corundum and spinel-type structures start to form after $160 \mathrm{~h}$ of milling as evidenced by XRD. An Fe doublet corresponding to $\mathrm{Fe}^{2+}$ in a ternary oxide is indeed concomitantly observed in Mössbauer spectra. 
Their formation is due to the high oxygen contents accumulated in the samples milled for very long times because of periodic vial openings for argon replacement. Further studies are underway to characterize the behavior of a near equiatomic $\mathrm{Fe}-\mathrm{V}$ sigma phase when milled in vacuum.

\section{References}

[1] T. Naohara, K. Shinohara, Trans. Japan Inst. Met. 28 (4) (1987) 273

[2] T. Ziller, G. Le Caer, O. Isnard, P. Cenedese, B. Fultz, Phys. Rev. B 65 (2002) 024204.

[3] P. Villars, L.D. Calvert, Pearson's Handbook of Crystallographic Data for Intermetallic Phases, American Physical Society for Metals, Metals Park, OH, 1991, p. 2246.

[4] B.F.O. Costa, G. Le Caer, N. Ayres de Campos, Phys. Stat. Sol. a 183 (2001) 235.

[5] B.F.O. Costa, G. Le Caer, B. Luyssaert, J. Alloys Compd. 350 (2003) 36.

[6] G. Martin, P. Bellon, Solid State Phys. 50 (1996) 189.

[7] H. Bakker, G.F. Zhou, H. Yang, Progr. Mater. Sci. 39 (1995) 159.

[8] H. Yang, H. Bakker, Mater. Sci. Eng. 181/A182 (1994) 1207.

[9] A.C. Lund, C. Schuh, Phys. Rev. Lett. 91 (2003) 235505.
[10] S. Odunuga, Y. Li, P. Krasnochtchekov, P. Bellon, R.S. Averback, Phys. Rev. Lett. 95 (2005) 045901.

[11] C. Suryanaryana, Progr. Mater. Sci. 46 (2001) 1.

[12] E. Gaffet, G. Le Caer, in: H.S. Nalwa (Ed.), Encyclopedia of Nanoscience and Nanotechnology, vol. 5, American Scientific Publishers, 2004, p. 91.

[13] Y. Ivanisenko, I. MacLaren, R.Z. Valiev, H.J. Fecht, Adv. Eng. Mater. 7 (2005) 1011.

[14] T. Koyano, K. Chatani, T. Fukunaga, U. Mizutani, Mater. Sci. Eng. A 181/A182 (1994) 1277.

[15] T. Fukunaga, M. Mori, M. Misawa, U. Mizutani, Mater. Sci. Forum 88-90 (1992) 663.

[16] L. Lanote, P. Matteazzi, J. Magn. Magn. Mater. 88 (1990) 58.

[17] B. Fultz, G. Le Caër, P. Matteazzi, J. Mater. Res. 4 (6) (1989) 1450.

[18] G. Le Caër, J.M. Dubois, J. Phys. E 12 (1979) 1083.

[19] G. Le Caër, P. Delcroix, T.D. Shen, B. Malaman, Phys. Rev. B 54 (1996) 12775.

[20] G. Le Caër, T. Ziller, P. Delcroix, C. Bellouard, Hyperfine Interactions 130 (2000) 45.

[21] T. Ziller, G. Le Caer, O. Isnard, P. Cenedese, B. Fultz, Phys. Rev. B 65 (2002) 024204;

T. Ziller, Ph.D. Thesis, INPL, Nancy, 2000.

[22] G. Shirane, D.E. Cox, S.L. Ruby, Phys. Rev. 125 (1962) 1158. 